\title{
CORRIGENDUM
}

\section{Association of the homeobox transcription factor, ENGRAILED 2, with autism spectrum disorder}

N Gharani, R Benayed, V Mancuso, LM Brzustowicz and JH Millonig

Molecular Psychiatry (2004) 9, 540. doi:10.1038/sj.mp.4001515

Correction to: Mol Psychiatry (2004) 9, 474-484. doi: 10.1038/sj.mp.4001498

Following publication of the above paper, the author has identified errors in the title of the article.

The correct title is 'Association of the homeobox transcription factor, ENGRAILED 2, with autism spectrum disorder', and the superscript designation for R Benayed should read 2, 3, 5 . 